\title{
LA DOCTRINA DEL LEVANTAMIENTO DEL VELO EN EL DERECHO PRIVADO CHILENO. Comentario a Sentencia de la Corte Suprema de 16 DE OCTUBRE DE 2017, ROL N ${ }^{\circ}$ 18.236-2017*
}

\section{LEÓN CARMONA FontaInE**}

\section{INTRODUCCIÓN}

En sentencia de octubre de 2017, la Corte Suprema ha dictado una sentencia que trata diversos asuntos vinculados al abuso de la persona jurídica y a la técnica del levantamiento del velo en asuntos de derecho privado.

En el presente comentario, junto con hacer una breve reseña del estado de la jurisprudencia en la materia, se tratan algunas cuestiones destacadas de la sentencia. En particular, se aborda (i) el rol que la Corte Suprema le otorga a la buena fe como criterio para determinar cuándo un deudor ha hecho uso abusivo de la persona jurídica, y (ii) la forma en que, según la Corte Suprema, puede aplicarse el levantamiento del velo en un proceso judicial.

\section{1) SÍNTESIS DEL CASO}

\section{(1.1.) LA DISCUSIÓN PLANTEADA POR LAS PARTES}

Neuroimagen S.A. dedujo demanda de cobro de pesos en contra de Megasalud S.A. (en adelante "Megasalud") solicitando que fuera condenada al pago de $\$ 90.822 .770$, más intereses y costas.

Fundó la demanda en que la sociedad Arauco Medicina Intregral S.A. le adeudaba la cantidad de $\$ 90.822 .770$ en virtud de cinco facturas impagas, deuda que habría sido cedida y asumida por Megasalud como consecuencia de un contrato de transferencia de activos celebrado entre la primitiva deudora, Arauco Medicina Integral S.A., y la nueva deudora y demandada en autos, Megasalud.

Fecha de recepción 21 de febrero de 2018.

Fecha de aceptación 23 de mayo de 2018.

** Licenciado en Derecho, Profesor de Filosofía del Derecho y de Seminario de Investigación en Jurisprudencia de la Corte Suprema, Pontificia Universidad Católica de Chile. Dirección postal: Avda. Libertador Bernardo O’Higgins Nº 340, Santiago, Chile. Correo electrónico: plcarmon@uc.cl. 
La demandada evacuó su contestación, oponiendo, en primer lugar, excepción de falta de legitimación pasiva. Para ello, sostuvo que quienes celebraron un contrato de transferencia de activos en realidad fueron, por una parte, Arauco Medicina Integral S.A. y, por la otra, Megasalud Oriente Limitada (en adelante "Megasalud Oriente"), siendo, esta última, una sociedad distinta de aquella en contra de quien se dirigía la demanda. Adicionalmente, y para el evento que se rechazare la excepción de falta de legitimación, Megasalud opuso excepción de prescripción.

$\mathrm{Al}$ evacuar la réplica, Neuroimagen S.A. afirmó que, de los documentos que fueron incorporados en la medida prejudicial, constaría que fue Megasalud quien asumió la obligación reclamada; agregando que, en todo caso, Megasalud Oriente sería una sociedad coligada de Megasalud, y que, "las obligaciones se producen entre patrimonios", motivo por el cual debería desecharse la excepción de falta de legitimación pasiva.

\section{(1.2.) LA DECISIÓN DE LOS TRIBUNALES DE INSTANCIA}

La demanda fue rechazada sin costas por el $23^{\text {er }}$ Juzgado de Letras en lo Civil de Santiago. Para rechazar la demanda, el juez de instancia sostuvo, en síntesis, (i) que no se habría acreditado que la demandada hubiere asumido la deuda reclamada en la demanda; y (ii) que si bien en una carta emanada de Megasalud se afirma que sería ella quien pagaría las facturas del caso, "en él se indica que el pago de tales facturas se haría conforme al convenio de compra de pasivos que se celebraría, mismo que no consta en autos", todo ello justamente porque el convenio de trasferencia de activos y pasivos habría sido celebrado por Megasalud Oriente y no por Megasalud, siendo solo esta última la sociedad demandada.

Conociendo del recurso de apelación deducido por la actora, la Corte de Apelaciones de Santiago confirmó la sentencia sin mayores consideraciones. En contra de esta última sentencia, la perdidosa dedujo recursos de casación en la forma y en el fondo.

\section{(1.3.) LA DECISIÓN DE LA CORTE SUPREMA}

Luego de rechazar el recurso de casación en la forma por las razones que ahí se expresan, la Corte Suprema acogió el recurso de casación en el fondo, anulando la sentencia recurrida y dictando sentencia de reemplazo, dando lugar a la demanda deducida por Neuroimagen S.A. en contra de Megasalud.

Para proceder de este modo, la Corte aplicó la técnica del levantamiento del velo societario, entendiendo (i) que entre Megasalud y Me- 
gasalud Oriente existía una identidad patrimonial por integrar ambas sociedades un mismo grupo empresarial con un controlador común; y (ii) que la primera había instrumentalizado en forma contraria a la buena fe la personalidad jurídica de la segunda, en tanto que, habiéndose comprometido Megasalud a asumir el pago de las facturas, finalmente habría pretendido quedar liberado de dicha responsabilidad, superponiendo a Megasalud Oriente como deudora de la obligación.

Para estos efectos, la Corte tuvo particularmente en cuenta que, si bien la transferencia de activos fue realizada por Arauco Medicina Integral S.A. y Megasalud Oriente, "con fecha 20 de octubre de 2010, el gerente comercial de Megasalud S.A., a través de una carta remitida a Neuroimagen S.A., informó que le pagaría la deuda reconocida por Arauco Medicina Integral S.A. de acuerdo al convenio de compra de pasivos entre Megasalud S.A. y Arauco Medicina Integral S.A., detallando las facturas objeto de este acuerdo". En este orden de ideas, la Corte Suprema razonó señalando que "la circunstancia de haber comparecido en actos preparatorios precontractuales Megasalud S.A. reconociendo la existencia de la deuda y asumiendo su obligación de pago en virtud de un contrato de compraventa de activos $y$ pasivos que celebraria con la deudora original, para luego proceder a celebrar esta última convención con una filial que controla, vulnera los principios de la buena fe que inspiran nuestro ordenamiento juridico"2.

A lo anterior, la Corte agregó que el abuso de la persona jurídica otorga al tercero defraudado una acción de inoponibilidad que "debe entenderse incluida en todas las acciones judiciales que persiguen el cumplimiento de una obligación que el deudor ha intentado evadir mediante la instrumentalización abusiva de una sociedad [...] sin que le exija al acreedor iniciar acciones para obtener la declaración de simulación, fraude pauliano $o$ cualquier otra encaminada a salvaguardar sus intereses, ya que ello implicaría de algún modo imponer dificultades adicionales al acreedor y facilitar la comisión del fraude" 3 .

Por estas consideraciones, nuestro Máximo Tribunal estimó que la sentencia recurrida incurrió en errores de derecho que influyeron sustancialmente en lo dispositivo del fallo, al acoger una excepción de falta de legitimación pasiva que no era procedente, infringiendo así los artículos 13, 1445, 1444, 1560 del Código Civil, 96, 101 y 102 de la Ley $N^{\circ}$ 18.045 .

\footnotetext{
1 Corte Suprema, 16 de octubre de 2017, Rol N 18.236-2017, "Neuroimagen S.A. con Megasalud S.A.", disponible en Base de Datos "Microjuris", cita online MJCH_MJJ51737, considerando $13^{\circ}$.

2 Corte Suprema, 16 de octubre de 2017, Rol N 18.236-2017, considerando $13^{\circ}$.

3 Corte Suprema, 16 de octubre de 2017, Rol No 18.236-2017, considerando $15^{\circ}$.
} 
En la sentencia de reemplazo, la Corte Suprema rechazó la excepción de falta de legitimación pasiva y rechazó asimismo la excepción de prescripción por las consideraciones que ahí se expresan, acogiendo en definitiva la demanda deducida por Neuroimagen S.A. y condenando a Megasalud al pago de $\$ 90.822 .770$, con reajustes desde el 20 de octubre de 2010, más intereses corrientes para operaciones reajustables, con costas.

\section{2) COMEnTARio}

La sentencia que comentamos constituye un aporte significativo para el entendimiento y aplicación de la técnica del levantamiento del velo en nuestro país. En efecto, entre otras cuestiones, este pronunciamiento de la Corte Suprema destaca (i) por reconocer que el abuso de la persona jurídica $-y$ el consecuente levantamiento del velo- puede ser por sí mismo fundamento suficiente para resolver una controversia jurídica; (ii) por el rol que le otorga a la buena fe como criterio para determinar cuándo un deudor ha hecho un uso abusivo de la persona jurídica; y, (iii) por definir la forma en que la técnica del levantamiento del velo puede aplicarse en un proceso judicial.

En el presente comentario nos detenemos brevemente a tratar estas cuestiones.

\section{(2.1.) CUESTIÓN PREVIA: EL ENTENDIMIENTO JURISPRUDENCIAL DE LA TÉCNICA DEL LEVANTAMIENTO DEL VELO}

Como cuestión previa, y antes de analizar los asuntos referidos, se debe tener presente que el fallo que aquí se comenta se inserta dentro de un conjunto significativo de sentencias de la Corte Suprema, cuyo origen se encuentra en el caso "Ultramar Agencia Maritima contra AGF Allianz Compañia de Seguros Generales S.A." de junio de $2009^{4}$, pero que se ha visto proliferado a partir del año $2016^{5}$, cuya nota común es la de recono-

4 Corte Suprema, 2 de junio de 2009, Rol N 1527-2008. "Ultramar Agencia Marítima Ltda con AGF Allianz Compañía de Seguros Generales S.A.”, disponible en Base de Datos "Westlaw", cita online CL/JUR/147/2009. Luego de este caso, las sentencias que inmediatamente le siguen, y que se refieran a la materia, son (i) Corte Suprema, 9 de marzo de 2010, Rol N²423-2008. "Pesca Cisne S.A. con Catrilef Hernández, Salomón Neh", disponible en base de datos "Westlaw", cita online CL/JUR/1676/2010; y (ii) Corte Suprema, 20 de junio de 2013, Rol No 1662-2013. "Empresa de Servicios Sanitarios del Bío Bío con Interagro Comercio y Ganado S.A", disponible en base de datos "Microjuris", cita online MJCH_MJJ35480.

5 En adición a la sentencia que comentamos, a partir del año 2016 la Corte Suprema ha dictado las siguientes sentencias que reconocen la aplicación de la técnica del levantamiento 
cer la aplicación de la doctrina del levantamiento del velo en materias de derecho privado.

Este conjunto de sentencias y, dentro de ellas, la que es materia de este comentario, contiene ciertas ideas fundamentales sobre el levantamiento del velo que permiten formularse una noción general del mismo y de los requisitos que deben reunirse para su aplicación, cuestión que da cuenta que en el máximo tribunal existe una comprensión bastante asentada de este instituto ${ }^{6}$. Así, el contexto jurisprudencial actual resulta sustancialmente distinto del descrito por un autor hace casi una década, señalando que, salvo excepciones, la práctica jurídica en Chile prefería otras alternativas al levantamiento del velo, como sería la responsabilidad extracontractual y la acción pauliana, entre otras ${ }^{7}$.

Pues bien, conforme a esta jurisprudencia de la cual la sentencia que comentamos es parte, el levantamiento del velo es una técnica judicial que permite a los tribunales ignorar o desestimar la personalidad jurídica de las sociedades y la separación de patrimonios, con el propósito de terminar los fraudes y abusos que se pretenden alcanzar por su intermedio ${ }^{8}$.

Con todo, se considera que la personalidad jurídica de las sociedades constituye un elemento fundamental del derecho, que ha contribuido

del velo en el derecho civil y comercial: (i) Corte Suprema, 17 de marzo de 2016, Rol No 9972-2015. "Sociedad Hotelera Santa Teresa Limitada con Luisa Grappiolo y otros", disponible en base de datos "Westlaw", cita online CL/JUR/1723/2016; (ii) CorTe SuPREMA, 23 de marzo de 2016, Rol No 2284-2015. "Ana Gutiérrez Garrido con Inversiones Leiva y Compañía Limitada y otros", disponible en base de datos "Westlaw", cita online CL/JUR/1914/2016; (iii) Corte Suprema, 17 de agosto de 2016, Rol N 25.887-2016. "Empresa Constructora Precon S.A. con Constructora Cachagua Bordemar Dos Limitada", disponible en base de datos "Westlaw", cita online CL/JUR/5887/2016; CorTe Suprema, 14 de marzo de 2017, Rol No 35.542-2016. "Eduardo Salvo Fuentes y otros con Inmobiliaria Bergneustadt Limitada"; (iv) Corte Suprema, 14 de marzo de 2017, Rol No 35.542-2016. "Eduardo Salvo Fuentes y otros con Inmobiliaria Bergneustadt Limitada", disponible en base de datos "Westlaw", cita online CL/JUR/901/2017; (v) Corte Suprema, 31 de mayo de 2017, Rol N 49.961-2016. "Banco del Estado de Chile con Sociedad José María Martínez e Hijos Limitada", disponible en base de datos "Westlaw", cita online CL/ JUR/4774/2017; y (vi) Corte Suprema, 9 de noviembre de 2017, Rol N³8.630-2017. "Patricio Iturriaga Grunert con Sociedad Continental Inmobiliaria y Servicios Limitada y otro", disponible en base de datos "Westlaw", cita online CL/JUR/7178/2017.

6 Cabe hacer notar que, tanto por las citas explícitas como por el contenido de las sentencias, se observa que sobre esta materia la Corte Suprema ha seguido el planteamiento de UgarTe. Ugarte Vial, Jorge (2012). "Fundamentos y acciones para la aplicación del Levantamiento del velo en Chile". Revista Chilena de Derecho, Vol. 39, №3, pp. 699-723.

7 Urbina Molfino, Ignacio (2011). "Levantamiento del velo corporativo. Sentencia de la Corte Suprema de 2 de junio de 2009". Revista Chilena de Derecho, Vol. 38, N 1, pp. 163171, p. 164.

8 Tal caracterización puede encontrarse con variaciones, además de en la sentencia que comentamos, en Corte Suprema, 2 de junio de 2009, Rol No 1527-2008; Corte Suprema, 17 de marzo de 2016, Rol No 9972-2015; Corte Suprema, 23 de marzo de 2016, Rol $\mathrm{N}^{\circ}$ 2284-2015, sentencia de reemplazo; Corte Suprema, 17 de agosto de 2016, Rol N ${ }^{\circ}$ 25.887-2016. 
substancialmente al desarrollo de la economía moderna. Por tanto, se afirma que el levantamiento del velo es un recurso excepcional, y que su abuso podría menoscabar la protección que se debe a las sociedades, a su personalidad jurídica y su patrimonio separado, elementos que la Corte Suprema califica como esenciales no solo desde un punto de vista jurídico, sino también económico?.

Se agrega finalmente que, siendo excepcional, la aplicación de esta técnica solo resulta procedente en la medida que se reúnan dos requisitos copulativos, a saber (i) la identidad personal o patrimonial entre una sociedad y uno o más de sus socios, administradores o sociedades relacionadas; y segundo, (ii) la instrumentalización abusiva de una sociedad o persona jurídica para la consecución de un fraude a la ley o a los derechos de terceros ${ }^{10}$.

\section{(2.2.) EL ABUSO DE LA PERSONA JURÍDICA Y EL CONSECUENTE LEVANTAMIENTO DEL VELO SON FUNDAMENTOS SUFICIENTES PARA DIRIMIR UNA CONTROVERSIA JURÍDICA}

Dicho lo anterior, el fallo que comentamos destaca, en primer lugar, por ser el primer caso en que la Corte Suprema resuelve un asunto de derecho civil patrimonial, sobre la base de prescindir de la personalidad jurídica de una sociedad y utilizar la técnica del levantamiento del velo como única $-\mathrm{o}$, al menos, principal y suficiente- motivación jurídica de la sentencia. Es la técnica del levantamiento del velo la que por sí misma resultó suficiente para que la Corte haya resuelto rechazar la excepción de falta de legitimación pasiva deducida por la demandada y, en definitiva, acoger la demanda.

En casos anteriores, en cambio, la Corte Suprema había hecho uso de esta técnica pero solo como una motivación adicional a las utilizadas para resolver la controversia, esto es a mayor abundamiento del fundamento principal de la decisión ${ }^{11}$; o bien había recurrido a este instituto para completar otra institución jurídica que, para estos efectos, podría calificarse como principal $^{12}$; o bien, reconociendo la procedencia del levanta-

\footnotetext{
9 En adición a la sentencia que comentamos, Corte Suprema, 17 de agosto de 2016, Rol N ${ }^{\circ}$ 25.887-2016, y Corte Suprema, 17 de marzo de 2016, Rol N 9972-2015a.

10 Con variaciones, y en adición a la sentencia que comentamos, estos requisitos aparecen formulados en forma explícita y sistemática en Corte Suprema, 17 de agosto de 2016, Rol N 25.887-2016, y Corte Suprema, 17 de marzo de 2016, Rol Nº 9972-2015. En sentencias previas también pueden encontrarse pero de forma menos sistemática.

11 Entre otras, Corte Suprema, 2 de junio de 2009, Rol N 1527-2008; Corte Suprema, 31 de mayo de 2017, Rol N 49.961-2016, considerando vigésimo.

12 Corte Suprema, 23 de marzo de 2016, Rol N²284-2015.
} 
miento del velo, no hacía uso de esta técnica en el caso particular por no reunirse los elementos de hecho necesarios para su procedencia ${ }^{13}$.

Esta cuestión tiene cierta relevancia, porque, al proceder de esta forma, la Corte Suprema parece situarse en la posición de quienes afirman que la doctrina del levantamiento del velo goza de una identidad propia, y tiene una fisonomía distinta de otras instituciones afines como son la simulación, el abuso del derecho y el fraude a la ley ${ }^{14}$.

\section{(2.3.) EL ROL DE LA BUENA FE COMO CRITERIO PARA DETERMINAR CUÁNDO HA EXISTIDO UN USO ABUSIVO DE LA PERSONA JURÍDICA}

La sentencia en comento destaca también por el rol que le otorga a la buena fe como criterio para determinar cuándo ha existido un abuso de la personalidad jurídica.

Según hemos visto, el segundo de los requisitos que la Corte Suprema exige para que pueda aplicarse el levantamiento del velo, consiste en la instrumentalización abusiva de la personalidad jurídica en fraude a la ley o a los derechos de terceros. En la práctica, la configuración de este requisito suele plantear dificultades.

En efecto, la separación de patrimonios -y la limitación de la responsabilidad para el caso de gran parte de las sociedades comerciales- que emana de la misma persona jurídica, conlleva de suyo que ciertas normas legales no se apliquen a los miembros de la sociedad individualmente considerados, y que ellos no respondan de las deudas sociales. Todo lo anterior, aun cuando exista una identidad material entre la sociedad y sus miembros ${ }^{15}$, y sin perjuicio de que ello pueda significar que uno o más terceros no vean satisfechas sus acreencias o bien que se alcance una posición jurídica que, de no existir la persona jurídica, sería prohibida por la ley.

La personalidad jurídica (y particularmente la de las sociedades comerciales de responsabilidad limitada) existe justamente para dar origen a una entidad responsable distinta de sus socios o accionistas, de modo que estos últimos no respondan de las obligaciones sociales con su patrimonio personal. Así, comentando la Ley N³918 sobre la sociedad de responsabilidad limitada (cuyo proyecto había redactado en su calidad de senador

13 Corte Suprema, 17 de agosto de 2016, Rol N² 25.887-2016; Corte Suprema, 17 de marzo de 2016, Rol No 9972-2015.

14 De esta opinión es López Díaz, Patricia (2009) La doctrina del levantamiento del velo y la instrumentalización de la persona jurídica. Santiago: LegalPublishing, 535 pp., pp. 76-77.

15 En este sentido el caso más paradigmático es el de la sociedad por acciones en donde el Código de Comercio permite que sea conformada por un solo accionista. Así, se contempla como parte de su funcionalidad y finalidad, que exista una total identificación entre el accionista y la sociedad. 
de la República), Luis Claro Solar señalaba que este nuevo tipo de sociedad venía a salvar los inconvenientes de que los socios pudieren verse afectados por responsabilidades y pérdidas sociales que no hubieren podido prever ni evitar en medio de la marcha normal de los negocios ${ }^{16}$, y es justamente en miras a lo anterior que las personas deciden formar esta clase de sociedades.

De esta forma, el solo hecho de que en el mundo de las relaciones jurídicas y económicas estos resultados se produzcan -como es que, como consecuencia de la existencia de un ente social o de la responsabilidad limitada de sus socios, un acreedor se vea imposibilitado de cobrar su crédito o bien que un determinado precepto legal no resulte aplicable-, no parece suficiente para que se configure un abuso de la persona jurídica y pueda aplicarse el levantamiento del velo: son resultados que el derecho tolera en atención a los beneficios sociales derivados de la personalidad jurídica. Todavía más, estos resultados incluso pueden ser, hasta cierto punto, queridos por quienes integran una sociedad; desde que es perfectamente lícito preferir un determinado tipo social por sobre otro para con ello salvar el patrimonio y responsabilidad personal de los socios o accionistas.

Pues bien: en este aspecto, el fallo que comentamos también hace una notable contribución. En efecto, junto con reconocer la relevancia tanto jurídica como económica de la separación de patrimonios que produce la persona jurídica, la Corte fundó el abuso del ente societario no tanto en que el acreedor se viera imposibilitado de cobrar su crédito, sino en que el deudor había usado de él en forma contraria a la buena fe, burlando, así, el cumplimiento de una obligación ${ }^{17}$. Al respecto, la Corte afirmó que "en esta materia el principio de la buena fe juega un rol trascendental", agregando que, en este caso, existiría por parte de Megasalud una instrumentalización de la persona jurídica, con infracción a la buena fe, por haber defraudado la apariencia y expectativa generada a Neuroimagen S.A., al afirmar, originalmente, en actos preparatorios, que sería ella quien asumiría la deuda de la que daban cuenta las facturas, para luego negar lo anterior, y sostener que el verdaderamente obligado sería Megasalud

16 Claro Solar, Luis. (1923) "La Ley Núm. 3918 de 14 de marzo de 1923 sobre Sociedades de Responsabilidad Limitada". Revista de Derecho y Jurisprudencia, Tomo XX, marzo a julio de 1923 , pp. 1-17, p. 2. Por su parte, en la Historia de la Ley $\mathrm{N}^{\circ} 3918$ se puede leer que se expresaba que el proyecto en cuestión "introduce en nuestra legislación civil una modificación de capital importancia encaminada a facilitar la formación de empresas comerciales, evitando los peligros de que están expuestos los socios de las sociedades colectivas y los socios gestores en las sociedades en comandita, por el hecho de no estar limitada por la ley su responsabilidad pecuniaria. Estima la Comisión oportuna y de particular conveniencia la creación entre nosotros de la sociedad limitada, en la creencia de que contribuirá eficazmente al desenvolvimiento de las actividades industriales y comerciales del pais".

17 Sobre el rol de la buena fe en el abuso de la persona jurídica, ver Ugarte (2012) 712. 
Oriente. Así, entonces, el elemento fundamental para determinar que existió un abuso de la persona jurídica, es la mala fe del que se ha aprovechado de ella.

Cabe hacer notar que, si bien en casos anteriores la Corte Suprema ya había reconocido que la doctrina del abuso de la persona jurídica encuentra su fundamento, entre otras instituciones, en la buena $\mathrm{fe}^{18}$, hasta el fallo que comentamos no existían pronunciamientos del Máximo Tribunal en que expresamente se considerara que el criterio para determinar si existió una instrumentalización abusiva del ente social, es si se hizo uso de él, de buena fe o mala fe.

Para algunos podría parecer insuficiente o incierto fundar el abuso de la persona jurídica en la buena fe, por tratarse de un principio de derecho, amplio por definición, y, por lo tanto, carente de concreción. Sin embargo, lo cierto es que justamente la amplitud de este principio es lo que lo vuelve útil para dar soluciones jurídicas a las más distintas situaciones, siendo ello quizás su mayor virtud ${ }^{19}$. Por lo demás, el rol de la buena fe como límite al ejercicio legítimo de la persona jurídica no debiera parecernos extraño, pues, como se ha hecho notar ${ }^{20}$, la buena fe ha sido extensamente tratada y acogida por la jurisprudencia como límite al ejercicio de derechos subjetivos. En realidad, la buena fe es justamente el elemento que permite reconocer la plena procedencia de la técnica del levantamiento del velo sin dejar de otorgar tutela y protección a la personalidad jurídica de las sociedades.

Así, entonces, siguiendo el criterio de la Corte Suprema, podría formularse la siguiente regla general: existe una instrumentalización abusiva de la personalidad jurídica cuando, haciendo un uso de ella contrario a la buena fe, se alcanza un resultado no querido por la ley o bien se burla el cumplimiento de una obligación. En otras palabras, para determinar si en un caso en concreto se ha abusado de la persona jurídica, no solo se habrá de analizar si el deudor pudo o no cobrar su crédito o si en definitiva se cumplió o no una obligación, sino que también si la persona jurídica se ha utilizado conforme a la lealtad, transparencia, honestidad y confianza que debe existir en todo el tráfico jurídico.

18 En tal sentido, Corte Suprema, 2 de junio de 2009, Rol No 1527-2008; Corte Suprema, 23 de marzo de 2016, Rol No 2284-2015; Corte Suprema, 14 de marzo de 2017, Rol No 35.542-2016.

19 En tal sentido, Boetsch Gillet, Cristián (2015) La buena fe contractual. Santiago: Ediciones UC, 188 pp., pp. 35-37.

20 Entre otros, Barros Bourie, Enrique (2006) Tratado de responsabilidad extracontractual. Santiago: Editorial Jurídica, 1230 pp., pp, 628-629 y Boetsch (2015), 49-52. 


\section{(2.4.) EL LEVANTAMIENTO DEL VELO SE HACE EFECTIVO MEDIANTE UNA ACCIÓN DE INOPONIBILIDAD QUE TENDRÍA UN CARÁCTER ACCESORIO}

Finalmente, cabe señalar que este fallo destaca porque, siguiendo lo planteado por UGARTE ${ }^{21}$ y luego replicado por VÁzQUEZ ${ }^{22}$, explicita de qué forma la técnica del levantamiento del velo puede hacerse efectiva. En efecto, la Corte sostiene que el abuso de la personalidad jurídica otorga al tercero defraudado una acción de inoponibilidad para que, en un caso concreto, se prescinda de uno o más atributos derivados de la personalidad jurídica de la sociedad de cuya estructura se ha abusado, agregando que dicha acción de inoponibilidad debe entenderse incluida en todas las acciones judiciales que persiguen el cumplimiento de una obligación que el deudor ha intentado evadir mediante la instrumentalización abusiva de una sociedad. La acción de inoponibilidad no sería entonces una acción autónoma e independiente, sino que, más bien, un accesorio o atributo de la acción mediante la cual se persigue el cumplimiento de una obligación ${ }^{23}$.

Esta solución tiene un notable valor. En efecto, resulta lógico que las acciones que buscan el cumplimiento de las obligaciones comprendan aquellos elementos necesarios para que sean eficaces, como es justamente la inoponibilidad del instituto mediante el cual se alcanzó el fraude. A su turno, la mera declaración de inoponibilidad no parece ser capaz de alcanzar por sí sola un resultado de relevancia jurídica; la inoponibilidad por lo general será un medio para alcanzar otro resultado jurídico y por lo mismo se ejercerá mediante algún tipo de acumulación de acciones. De paso, además, esta forma de entender la inoponibilidad permite solucionar el problema del plazo de su prescripción: por consistir en una emanación del mismo arbitrio que ejerza el acreedor para hacer efectivo su derecho, la acción de inoponibilidad prescribirá junto con la acción principal.

UGARTE (2012) 717-718.

VÁsquez Palma, María (2014) "Sobre la limitación de responsabilidad en el derecho de sociedades y su posible extensión en el contexto de modernización”. Revista de Derecho (Valdivia), Vol. XXVII, Nº 2, pp. 105-132, pp. 127-128.

23 Sobre la acción de inoponibilidad en general y del tipo de acumulación de acciones que se puede utilizar ver trabajo de Romero. Romero Seguel, Alejandro Romero Seguel, A. (2011) "La acción para la declaración de inoponibilidad de un acto o contrato". En Zúñiga Tejos, Álex (coordinador): Estudios de Derecho Privado. Libro homenaje al jurista René Abeliuk Manasevich. Santiago: Editorial Jurídica, pp. 259-261. Más en general, cabe hacer notar que, aun cuando no refiriéndose a la acción de inoponibilidad, la doctrina procesal suele reconocer que existen categorías de relaciones entre las diversas acciones, una de las cuales es la relación de accesoriedad. Así en Romero Seguel, Alejandro (2014) Curso de Derecho Procesal Civil. La acción y protección de los derechos. Santiago: LegalPublishing, 238 pp., p. 127; y Núnéz Ojeda, Raúl y Pérez Ragone, Álvaro (2013) Manual de Derecho Procesal Civil, Parte General. Santiago: LegalPublishing, 486 pp., p. 174. 
Creemos, no obstante, que la caracterización que la Corte Suprema hace de la inoponibilidad, es un tanto equívoca, y requiere de algunas precisiones. La sentencia no permite entender con claridad si lo que la Corte Suprema sostiene -cuando afirma que la acción de inoponibilidad está incluida en la acción que busca el cumplimiento de una obligación-, es que el juez puede siempre de oficio declarar la inoponibilidad de la persona jurídica, aun cuando tal cuestión no haya formado parte de lo debatido en juicio, o bien algo distinto. Tampoco se comprende bien cómo una acción, propiamente tal, podría entenderse interpuesta en un juicio sin requerir que se exprese su petición concreta. Todavía más, estos planteamientos parecieran contravenir el principio dispositivo que rige la acción del juez en el proceso civil y, además, no se condicen con acciones análogas, como la declarativa de nulidad, en donde el legislador solo por excepción permite que la nulidad absoluta $-y$ no la relativa- sea declarada de oficio, exclusivamente cuando aparezca de manifiesto en el acto o contrato.

Por nuestra parte, pensamos que, procesalmente, la inoponibilidad de la persona jurídica puede adoptar la forma de una acción propiamente tal (en cuyo caso deberá ser pedida bajo dicho concepto, de manera expresa y formal, aun cuando deba acumularse a otra acción), o bien puede resultar del examen de la legitimación que deba hacer el juez y, por ello, ser declarada, pero esto solo en la medida que los elementos de hecho de la inoponibilidad formen parte de la causa de pedir de la cuestión debati$\mathrm{da}^{24}$. Nótese, en este sentido, que los elementos de hecho de la inoponibilidad de la persona jurídica podrán integrar la causa de pedir no solo por lo expresado en la demanda, sino que también por lo que se señale en la réplica, al controvertirse la falta de legitimación pasiva, alegada por el demandado, u otra excepción análoga, conforme lo permite el art. 312 del Código de Procedimiento Civil.

Esta última forma procesal de la inoponibilidad es la que pareciera condecirse con el caso comentado, en donde la inoponibildad del ente jurídico no fue pedida como una acción propiamente tal, sino que surgió a propósito de la legitimación; y en donde sus fundamentos de hecho integraron la causa de pedir de lo debatido en juicio. En efecto, frente a la acción de cobro de facturas deducida por Neurogimagen S.A., Megasalud opuso excepción de falta de legitimación pasiva, replicando el primero, entonces, que de los documentos incorporados en la medida prejudicial constaba que fue Megasalud quien asumió la obligación reclamada, que,

24 Sobre esta cuestión cabe tener presente que las situaciones legitimantes pueden ser también elementos de la causa de pedir. Así, por ejemplo, se ha señalado que en una obligación contractual la existencia de un vínculo previo entre las partes determina a los sujetos legitimados (Romero (2014) 93); vínculo contractual que integrará también la causa de pedir de cualquier acción contractual que se ejerza a propósito de dicho contrato. 
en todo caso, Megasalud Oriente era una sociedad coligada de Megasalud, y que, en realidad, "las obligaciones se producen entre patrimonios".

\section{Bibliografía}

Barros Bourie, Enrique (2006). Tratado de responsabilidad extracontractual. Santiago: Editorial Jurídica.

Boetsch Gillet, Cristián (2015). La buena fe contractual. Santiago: Ediciones UC.

Claro Solar, Luis (1923). "La Ley Núm. 3918 de 14 de marzo de 1923 sobre Sociedades de Responsabilidad Limitada". Revista de Derecho y Jurisprudencia, Tomo XX, marzo a julio de 1923, pp. 1-17.

López DíAz, Patricia (2009). La doctrina del levantamiento del velo y la instrumentalización de la persona jurídica. Santiago: Legal Publishing.

Núñez Ojeda, Raúl y Pérez Ragone, Álvaro (2013). Manual de Derecho Procesal Civil, Parte General. Santiago: LegalPublishing.

Romero Seguel, Alejandro (2011): "La acción para la declaración de inoponibilidad de un acto o contrato". En Zúńiga Tejos, Aléx (coordinador): Estudios de Derecho Privado. Libro homenaje al jurista René Abeliuk Manasevich. Santiago: Editorial Jurídica.

Romero Seguel, Alejandro (2014). Curso de Derecho Procesal Civil. La acción y protección de los derechos. Santiago: LegalPublishing

Ugarte VIaL, Jorge (2012). "Fundamentos y acciones para la aplicación del Levantamiento del velo en Chile". Revista Chilena de Derecho, Vol. 39, $\mathrm{N}^{\circ}$ 3, pp. 699-723.

Urbina Molfino, Ignacio (2011). "Levantamiento del velo corporativo. Sentencia de la Corte Suprema de 2 de junio de 2009". Revista Chilena de Derecho, Vol. 38, N 1, pp. 163-171.

VÁsquez Palma, María (2014). "Sobre la limitación de responsabilidad en el derecho de sociedades y su posible extensión en el contexto de modernización”. Revista de Derecho (Valdivia), Vol. XXVII, N² 2, pp. 105-132.

\section{JURISPRUDENCIA}

Corte Suprema, 2 de junio de 2009, Rol No 1527-2008. "Ultramar Agencia Marítima Ltda con AGF Allianz Compañía de Seguros Generales S.A.". Disponible en base de datos "Westlaw", cita online CL/JUR/147/2009. 
Corte Suprema, 9 de marzo de 2010, Rol N² 2423-2008. "Pesca Cisne S.A. con Catrilef Hernández, Salomón Neh". Disponible en base de datos "Westlaw", cita online CL/JUR/1676/2010

Corte Suprema, 20 de junio de 2013, Rol No 1662-2013. "Empresa de Servicios Sanitarios del Bío Bío con Interagro Comercio y Ganado S.A.". Disponible en base de datos "Microjuris", cita online $\mathrm{MJCH}_{-}$ MJJ35480.

Corte Suprema, 17 de marzo de 2016, Rol N 9972-2015. "Sociedad Hotelera Santa Teresa Limitada con Luisa Grappiolo y otros". Disponible en base de datos "Westlaw", cita online CL/ JUR/1723/2016.

Corte Suprema, 23 de marzo de 2016, Rol No 2284-2015. "Ana Gutiérrez Garrido con Inversiones Leiva y Compañía Limitada y otros". Disponible en base de datos "Westlaw", cita online CL/ JUR/1914/2016.

Corte Suprema, 17 de agosto de 2016, Rol N² 25.887-2016. "Empresa Constructora Precon S.A. con Constructora Cachagua Bordemar Dos Limitada". Disponible en base de datos "Westlaw", cita online CL/JUR/5887/2016.

Corte Suprema, 14 de marzo de 2017, Rol No 35.542-2016. "Eduardo Salvo Fuentes y otros con Inmobiliaria Bergneustadt Limitada". Disponible en base de datos "Westlaw", cita online CL/ JUR/901/2017.

Corte Suprema, 31 de mayo de 2017, Rol No 49.961-2016. "Banco del Estado de Chile con Sociedad José María Martínez e Hijos Limitada". Disponible en base de datos "Westlaw", cita online CL/ JUR/4774/2017.

Corte Suprema, 9 de noviembre de 2017, Rol No 38.630-2017. "Patricio Iturriaga Grunert con Sociedad Continental Inmobiliaria y Servicios Limitada y otro". Disponible en base de datos "Westlaw", cita online CL/JUR/7178/2017. 